\title{
A HIGIENE BUCAL DE BEBÊS EDÊNTULOS E SUA INFLUÊNCIA NA MICROBIOTA BUCAL: OS PROFISSIONAIS DE SAÚDE DEVEM PRECONIZÁ-LA? - REVISÃO CRÍTICA
}

\author{
Oral hygiene in edentulous infants and its influence on oral microbiota: \\ should the health professionals recommend it? - a critical review
}

\author{
(DDalila Miranda de Jesusa, (DLilian Lopes Barbosaa, (DThais Manzano Parisottob, \\ (D) Rogério Lacerda dos Santos ${ }^{a}$, (D) Hugo Lemes Carloa, (D) Fabíola Galbiatti de Carvalho
}

\section{RESUMO}

Introdução: A indicação de higiene bucal em bebês edêntulos entre os profissionais de saúde ainda é controversa, sendo necessária a busca científica sobre esta indicação e a padronização da informação. Objetivo: Investigar criticamente as evidências relacionadas a indicação da higiene bucal para bebês edêntulos. Métodos: A busca de artigos foi realizada nas bases de dados PubMed, LILACS e Google Scholar, de modo a avaliar a seguinte pergunta: "A higienização da cavidade bucal de bebês edêntulos pode influenciar a microbiota bucal?”. Uma busca em 8 livros de Odontopediatria também foi realizada. Resultados: Foram encontrados 317 artigos (167-PubMed, 146-Google Scholar e 4-LILACS). Não foram encontrados estudos primários que avaliaram o efeito da higiene bucal em bebês edêntulos na microbiota, impossibilitando a condução de revisão sistemática. Assim, para a revisão foram incluídos 6 estudos que investigaram micro-organismos na cavidade bucal de bebês edêntulos e o papel das imunoglobulinas salivares. Dentre os livros avaliados, somente 4 indicaram a higiene bucal em bebês edêntulos. Conclusão: Diante dos dados analisados, não existem estudos primários que avaliaram o efeito da higienização na microbiota bucal de bebês edêntulos. Torna-se relevante a condução de estudos clínicos para obtenção de evidências científicas sobre a indicação ou não da higienização da cavidade bucal de bebês edêntulos.

Palavras-chave: Boca edêntula. Recém-nascido. Higiene bucal. Microbiota.

\section{ABSTRACT}

Introduction: The indication of oral hygiene in edentulous babies is still controversial among health professionals, being necessary the search of this recommendation and the standardization of information. Objective: To investigate critically the evidence related to the indication of oral hygiene for edentulous babies. Methods: The search for articles was performed in the PubMed, LILACS and Google Scholar databases, in order to assess the following question: "Can oral cavity hygiene of edentulous babies influence oral microbiota?" A search in 8 books of Pediatric Dentistry was also performed. Results: 317 articles were found (167-PubMed, 146-Google Scholar and 4-LILACS). There were no primary studies that evaluated the effect of oral hygiene of edentulous infants on microbiota, which impair the conduction of a systematic review. Thus, it was included for this review six studies that investigated microorganisms in the oral cavity of edentulous infants and the role of salivary immunoglobulins. Among the textbooks evaluated, only 4 indicated the oral hygiene in edentulous infants. Conclusion: According to the data, there are no primary studies that assessed the effect of oral hygiene in the oral microbiota of edentulous babies. It is relevant to conduct clinical studies in order to obtain scientific evidence about the indication or no of the oral hygiene in edentulous babies.

Keywords: Mouth, edentulous. Infant, newborn. Oral hygiene. Microbiota.

aDepartamento de Odontologia, Universidade Federal de Juiz de Fora, Campus Governador Valadares, Governador Valadares, MG, Brasil. ’baboratório de Biologia Molecular de Microrganismos, Universidade São Francisco, Bragança Paulista, SP, Brasil.

Autora de correspondência: Profa. Fabíola Galbiatti de Carvalho - E-mail: fabigalbi@yahoo.com.br

Data de envio: 06/04/2020 | Data de aceite: 28/07/2020 


\section{INTRODUÇÃO}

A cárie dentária é considerada uma doença que ainda acomete as crianças na primeira infância ${ }^{1}$. Os fatores primários relacionados à sua etiologia são a presença de bactérias cariogênicas, principalmente Streptococcus mutans e Lactobacillus; o consumo de carboidratos fermentáveis, principalmente a sacarose; e a presença de hospedeiro e/ou superfície dentária susceptíveis; os quais podem interagir em determinado período de tempo².

A realização da higiene bucal associada a uma dieta equilibrada livre de sacarose é essencial para a prevenção da cárie ${ }^{3}$. Na literatura está fundamentado que a higiene bucal deve ser iniciada a partir da erupção do primeiro dente decíduo ${ }^{3-5}$, no entanto, nos casos de bebês edêntulos, ainda existe controvérsia entre os profissionais da área da saúde (médicos, enfermeiros e cirurgiões dentistas) sobre a indicação da higiene bucal, e não é raro verificar a indicação da higiene bucal antes da erupção dentária por profissionais ${ }^{6,7}$.

A justificativa para esta indicação é pautada na hipótese de que a higiene pode prevenir a colonização de micro-organismos na cavidade bucal, que possam ocasionar, posteriormente, doenças como a cárie; como também pode habituar a criança com a manipulação da cavidade bucal, promovendo facilidade durante a higiene quando da erupção dos dentes ${ }^{6-11}$.

É importante ressaltar que apesar da cavidade bucal dos bebês edêntulos apresentar colonização de bactérias, as mesmas não são responsáveis pela cárie da primeira infância, visto que esta é uma patologia multifatorial ${ }^{2}$. Somente a colonização precoce de bactérias não promove o aumento da prevalência da cárie, já que a colonização é transitória e a realização da higiene bucal após o irrompimento dos primeiros dentes pode ser suficiente para prevenção de patologias que acometem a cavidade bucal, principalmente a cárie ${ }^{12}$.

A microflora que se forma na cavidade bucal de bebês é composta por vários micro-organismos que são importantes para o desenvolvimento do sistema imune dos bebês ${ }^{13}$. Além disso, são encontradas imunoglobulinas, em especial a imunoglobulina A (IgA), que é a primeira linha de defesa imunológica das mucosas ${ }^{12}$, com isso, a higiene bucal poderia gerar desequilíbrios no meio bucal e aumentar o risco de infecções nos bebês edêntulos.

A higiene bucal de bebês edêntulos encontrada na literatura é realizada, principalmente, com compressa de gaze ou ponta de fralda úmida em água filtrada realizando a limpeza nos rebordos e língua do bebê ${ }^{6,7}$. Porém, existe controvérsia entre os profissionais da saúde sobre a indicação da higiene bucal em bebês edêntulos. Torna-se então necessário buscar as evidências científicas que suportem ou não esta recomendação, padronizando a informação a ser transmitida aos pais e responsáveis.

Desta forma, o presente estudo possui o objetivo de investigar criticamente a literatura quanto às evidências científicas relacionadas à higienização da cavidade bucal de bebês edêntulos. Para este fim, a pergunta de pesquisa desta revisão (PICO question) foi "A higienização da cavidade bucal de bebês edêntulos pode influenciar a microbiota bucal?', sendo composta dos seguintes elementos: P (paciente): cavidade bucal de bebês edêntulos; I (intervenção): higiene; O (resultado): micro-organismos, microbiota bucal.

\section{REVISÃo DE LITERATURA}

O conhecimento da colonização microbiana na cavidade bucal de bebês desde o nascimento fornece informações sobre os períodos de colonização de grupos de micro-organismos, inclusive da colonização de bactérias cariogênicas, o que poderia contribuir para a avaliação da necessidade ou não de realização de higiene da cavidade bucal de bebês antes da erupção dentária. 
A presença de micro-organismos na cavidade bucal dos bebês edêntulos se inicia nas primeiras horas após seu nascimento, sendo considerada estéril até 10h ou 24 h após o nascimento ${ }^{12}$. Isto ocorre devido a uma maior susceptibilidade dos bebês à colonização microbiana, já que seus anticorpos específicos, como IgA, IgE e IgM, ainda estão em pequenas quantidades ou ausentes ${ }^{12}$. Este fato possibilita a formação da microbiota bucal, estando favorável à colonização de micro-organismos que podem ser transmitidos durante o parto, principalmente se for parto normal, ou pelos cuidadores da criança, como pais ou enfermeiros ${ }^{12,14}$.

No nascimento e durante os primeiros meses de vida, a mucosa bucal se torna um nicho para a colonização bacteriana ${ }^{12}$. Streptococcus salivarius é a espécie bacteriana colonizadora pioneira da cavidade bucal, sendo detectada 8 horas após o nascimento ${ }^{12}$. Esta espécie representa até $98 \%$ da microbiota bucal antes da erupção dos dentes e possui aderência em língua e mucosa da bochecha ${ }^{15}$. A atividade metabólica das espécies pioneiras altera o meio ambiente bucal providenciando condições aceitáveis para colonização de outras espécies, sendo mais prevalentes micro-organismos aeróbios como Streptococcus e Staphylococcus, principalmente Staphylococcus epidermidis, Streptococos viridans e alguns bacilos gram-negativos ${ }^{12}$.

A colonização tardia de micro-organismos é assim considerada após a erupção dos dentes. Streptococcus sanguinis coloniza a cavidade bucal em torno dos 9 meses de idade da criança, sendo colonização dente-dependente e é associada com o tempo de erupção dentária, reduzindo em número na cavidade após a colonização por Streptococcus mutans ${ }^{7}$. Com relação ao principal micro-organismo relacionado à cárie dentária, Streptococcus mutans, existem dois estudos que citaram sua colonização em mucosa detectado em crianças de 2-3 meses de idade ${ }^{16}$ e anterior a erupção dentária ${ }^{17}$. Entretanto, essa colonização pode ser transitória na cavidade bucal devido as características descamativas da mucosa oral. Além disso, outros estudos mostraram que a colonização de $S$. mutans ocorre somente após a erupção dentária, devido a sua capacidade de aderência em superfícies duras ${ }^{12,14}$.

Desta forma, no primeiro ano de vida, as espécies mais prevalentes na cavidade bucal de bebês são Streptococcus, Staphylococcus, Neisseria, Lactobacillus, Veilonella, Actinomyces e Fusobacteria ${ }^{14,18}$, sendo que a presença destes micro-organismos, mesmo na cavidade bucal edêntula, é um processo no qual diferentes espécies de bactérias possuem diferentes momentos para sua colonização ${ }^{19,20}$.

A imunoglobulina A (IgA) é a principal imunoglobulina encontrada na saliva, sendo sua função principal a proteção das mucosas orais ${ }^{12}$. Embora a saliva dos recém-nascidos contenha pouca ou nenhuma IgA, esta concentração aumenta significativamente durante as primeiras semanas de vida ${ }^{12}$. Este aumento ocorre devido as imunoglobulinas presentes no leite materno, que irão proteger a cavidade bucal dos bebês, principalmente nos seis meses iniciais, onde é preconizado que seja de uso exclusivo.

Amostras de saliva coletadas pelo menos 4h após a amamentação comprovam que existe um aumento significativo da concentração de imunoglobulina, principalmente IgA, na cavidade bucal dos bebês que se alimentam do leito materno ${ }^{21}$. Além disso, pode ser observado um aumento significativo nos níveis de IgA e IgM na saliva durante o $1^{\circ}$ mês de vida, especialmente na segunda e terceira semanas também em bebês alimentados com combinação de leite materno e fórmula ${ }^{17}$.

Sendo assim, a higienização precoce da cavidade bucal dos bebês edêntulos pode interferir nos níveis de imunoglobulinas presentes, gerando sua remoção da cavidade bucal e alterando a proteção da mucosa, principalmente dos bebês que ainda não apresentam grandes quantidades de IgA salivar ou que não fazem aleitamento materno ${ }^{12}$. 


\section{MATERIAIS E MÉTODOS}

O desenvolvimento desta revisão crítica da literatura foi realizado em maio de 2018, e atualizada em novembro de 2018, com uma pesquisa nas bases de dados PubMed, LILACS e Google Scholar. A estratégia de busca utilizada na base PubMed foi: (infant, newborn [mesh] OR infant [mesh] OR mouth, edentulous [mesh] OR edentulous [mesh] OR babies OR baby) AND (oral hygiene [mesh] OR dental hygiene OR oral cavity) AND (microorganisms oral* OR microbiota oral). Na base de dados LILACS foi utilizado a busca: (infant, newborn OR infant OR mouth, edentulous OR edentulous OR babies OR baby) AND (oral hygiene OR dental hygiene OR oral cavity) AND (microorganisms oral OR microbiota oral). Na base Google Scholar os termos de busca utilizados foram: higiene E limpeza E cavidade bucal E bebês edêntulos. Não foi inserido na busca restrição de língua na escrita dos artigos e ano de publicação.

Os artigos foram selecionados considerando os seguintes critérios de inclusão: ensaios clínicos randomizados; ensaios clínicos não randomizados; estudos observacionais; estudos que investigaram a higiene bucal em bebês edêntulos com coleta de micro-organismos. Os critérios de exclusão foram: revisões de literatura; estudos em animais; relatos de caso; cartas ao editor; estudos de micro-organismos não relacionados à cavidade bucal; estudos de avaliação da microbiota em pacientes idosos edêntulos; estudos de avaliação da microbiota em pacientes implantados; estudos de avaliação de microbiota relacionada à doença periodontal e gestantes; estudos não relacionados à PICO question (principalmente estudos de microbiota não relacionados à cavidade bucal).

Os artigos encontrados na busca eletrônica foram organizados em documento para a leitura dos títulos e resumos, de modo a cruzar os artigos encontrados nas bases de dados. Foram contabilizados os artigos de ambas as bases verificando os coincidentes e não coincidentes. Desta forma, os artigos foram selecionados de acordo com os critérios de inclusão e exclusão, por dois examinadores calibrados. A discrepância entre os dois examinadores para inclusão ou exclusão dos artigos foi discutida até o alcance do consenso para seleção. Em seguida, foram selecionados os artigos para a leitura na íntegra, de modo que apenas os artigos na língua inglesa foram incluídos.

Uma busca nas edições de livros textos de Odontopediatria disponíveis nas bibliotecas das duas universidades dos autores do estudo também foi realizada para investigar o que os autores preconizavam quanto a indicação de limpeza da cavidade bucal de bebês edêntulos, como realizá-la e qual a evidência científica relacionada à sua indicação ou não. Para inclusão dos livros, os examinadores inicialmente acessaram seus índices para averiguar se abordavam os temas de Odontologia para Bebês e de Controle de biofilme na infância, e, em seguida prosseguiam com a leitura dos capítulos para encontrar a informação sobre higiene bucal em bebês edêntulos.

Os resultados dos artigos incluídos e excluídos, e dos livros textos de Odontopediatria foram organizados em forma de tabela para análise descritiva.

\section{RESULTADOS}

Foram encontrados no total 317 artigos, sendo 167 na base de dados PubMed, 146 no Google Scholar e 4 no LILACS, os quais foram analisados segundo os critérios de elegibilidade descritos na metodologia. Na leitura de títulos e resumos de todos os artigos foi observado que não existiam estudos clínicos e observacionais sobre a coleta de micro-organismos na cavidade bucal de bebês edêntulos associada à higiene da cavidade bucal, não sendo possível responder a PICO. Entretanto, foram encontrados estudos que investigaram micro-organismos presentes na cavidade bucal de bebês edêntulos ( 4 na base de dados PubMed, 
1 no LILACS) $)^{14,16,18-20}$ e um estudo que investigou o papel das imunoglobulinas salivares (1 estudo na base de dados PubMed) ${ }^{21}$, os quais descreveram resultados relevantes a PICO e foram incluídos para a discussão do artigo.

A Tabela 1 demonstra o número de artigos que foram excluídos de acordo com os critérios de elegibilidade e bases de dados.

Tabela 1: Número de artigos excluídos de acordo com os critérios de exclusão e base de dados.

\begin{tabular}{llll}
\hline Critérios de exclusão & PubMed & Google Scholar & LILACS \\
\hline Revisão de literatura & 5 & 11 & 0 \\
Estudo em animais & 4 & 1 & 0 \\
$\begin{array}{l}\text { Estudos de micro-organismos na cavidade } \\
\text { bucal sem avaliar a higiene bucal }\end{array}$ & 65 & 10 & 0 \\
$\begin{array}{l}\text { Estudos de micro-organismos na cavidade } \\
\text { bucal apenas de bebês com dentes }\end{array}$ & 0 & 0 & 1 \\
erupcionados & & & 0 \\
$\begin{array}{l}\text { Estudos de avaliação da microbiota em } \\
\text { pacientes edêntulos idosos }\end{array}$ & 10 & 7 & 0 \\
$\begin{array}{l}\text { Estudos de avaliação da microbiota em casos } \\
\text { de implantes dentários }\end{array}$ & 19 & 10 & 0 \\
$\begin{array}{l}\text { Estudos de avaliação da microbiota em casos } \\
\text { de doença periodontal }\end{array}$ & 3 & 8 & 0 \\
$\begin{array}{l}\text { Estudos relacionados à cavidade bucal de } \\
\text { gestantes }\end{array}$ & 0 & 12 & 2 \\
Estudos não relacionados a PICO question & 56 & 87 & 3 \\
\hline Total & 162 & 146 & \\
\hline
\end{tabular}

A Tabela 2 apresenta os 6 artigos que foram selecionados pelos critérios de inclusão, com as informações relativas ao tipo de estudo, descrição do estudo e grupos, amostra e os principais resultados encontrados. 
Tabela 2: Artigos incluídos com informações relacionadas ao tipo de estudo, descrição do estudo e grupos, número de participantes e os principais resultados encontrados.

\begin{tabular}{|c|c|c|c|c|}
\hline Autores/ano & $\begin{array}{l}\text { Tipo de } \\
\text { estudo }\end{array}$ & $\begin{array}{l}\text { Descrição do estudo/ } \\
\text { Grupos }\end{array}$ & Amostra & $\begin{array}{l}\text { Principais resultados } \\
\text { encontrados }\end{array}$ \\
\hline $\begin{array}{l}\text { Long } \\
\text { e Swenson } \\
(1976)^{18}\end{array}$ & $\begin{array}{l}\text { Experimental } \\
\text { (Laboratorial) }\end{array}$ & $\begin{array}{l}\text { Coleta de amostras } \\
\text { de células epiteliais } \\
\text { da língua e bochecha } \\
\text { dos bebês a termo } \\
\text { avaliadas em testes } \\
\text { de aderência com } \\
\text { cepas de S. salivarius, } \\
\text { S. mitis, S. mutans e } \\
\text { Escherichia coli }\end{array}$ & $\begin{array}{l}32 \text { bebês } \\
\text { a termo, } \\
\text { saudáveis } \\
\text { e com } \\
\text { menos de } \\
12 \text { horas de } \\
\text { idade }\end{array}$ & $\begin{array}{l}\text { Com menos de } 12 \text { horas de } \\
\text { idade, pouca ou nenhuma } \\
\text { aderência de bactérias foi } \\
\text { observada às células epite- } \\
\text { liais coletadas da boche- } \\
\text { cha e língua dos bebês. } \\
\text { Após a incubação, } \\
\text { S. salivarius e S. mitis mos- } \\
\text { traram alta aderência às } \\
\text { células epiteliais. Baixa ou } \\
\text { nenhuma aderência de } \\
\text { S. mutans às células epite- } \\
\text { liais foi observada. }\end{array}$ \\
\hline $\begin{array}{l}\text { Könönen } \\
\text { et al. (1992) }\end{array}$ & $\begin{array}{l}\text { Experimental } \\
\text { (Laboratorial) }\end{array}$ & $\begin{array}{l}\text { Mães: coleta da } \\
\text { saliva estimulada por } \\
\text { parafina; } \\
\text { Bebês: amostras da } \\
\text { mucosa e de saliva } \\
\text { não estimulada por } \\
\text { parafina }\end{array}$ & $\begin{array}{l}30 \text { mães } \\
(21-41 \\
\text { anos) e } \\
\text { seus bebês } \\
\text { edêntulos } \\
\text { (1-7 meses) }\end{array}$ & $\begin{array}{l}\text { Foi identificado nas } 30 \\
\text { mães a presença de } \\
\text { Fusobacterium nucleatum, } \\
\text { e em } 29 \text { a presença de } \\
\text { Prevotella melaninogenica. } \\
\text { Nos bebês a quantidade } \\
\text { desses micro-organismos } \\
\text { foi o dobro da quantidade; } \\
\text { houve correlação positiva } \\
\text { somente entre a concen- } \\
\text { tração bacteriana salivar } \\
\text { materna e dos bebês } \\
\text { para P. melaninogenica. Foi } \\
\text { especulado que a saliva } \\
\text { materna pode ser uma } \\
\text { fonte de colonização de } \\
\text { anaeróbios gram-negati- } \\
\text { vos na microflora de bebês } \\
\text { edêntulos. }\end{array}$ \\
\hline $\begin{array}{l}\text { Tappuni } \\
\text { e Challa- } \\
\text { combe } \\
(1994)^{21}\end{array}$ & $\begin{array}{l}\text { Experimental } \\
\text { (Laboratorial) }\end{array}$ & $\begin{array}{l}\text { Coleta de saliva } \\
\text { para determinar a } \\
\text { concentração de IgA } \\
\text { e sub-classe de IgA } \\
\text { em: mães com idade } \\
\text { entre } 21 \text { e } 38 \text { anos; } \\
\text { bebês edêntulos com } \\
\text { idade entre } 2 \text { a } 12 \\
\text { meses e crianças com } \\
\text { idade entre } 1 \text { e } 4 \text { anos } \\
\text { e } 3 \text { meses. }\end{array}$ & $\begin{array}{l}101 \text { sujei- } \\
\text { tos } \\
\text { ( } 28 \text { mães; } \\
44 \text { bebês } \\
\text { edêntulos } \\
\text { e } 29 \text { crian- } \\
\text { ças) }\end{array}$ & $\begin{array}{l}\text { Os níveis das imunoglobu- } \\
\text { linas IgA, IgA1 e IgA2 foram } \\
\text { mais baixos no grupo } \\
\text { edêntulos comparado } \\
\text { aos dentados. O grupo } \\
\text { adulto (mães) apresentou } \\
\text { valores mais altos de IgA, } \\
\text { lgA1 e IgA2 em relação } \\
\text { aos outros dois grupos. Os } \\
\text { níveis de IgA1 e lgA2 foram } \\
\text { semelhantes para todos os } \\
\text { grupos. Foi concluído que } \\
\text { a concentração de IgA e } \\
\text { subclasses não são diferen- } \\
\text { tes entre bebês edêntulos } \\
\text { e crianças dentadas, e } \\
\text { não alcançam os níveis do } \\
\text { adulto até } 2 \text { anos de idade }\end{array}$ \\
\hline
\end{tabular}




\begin{tabular}{|c|c|c|}
\hline Autores/ano & $\begin{array}{l}\text { Tipo de } \\
\text { estudo }\end{array}$ & $\begin{array}{l}\text { Descrição do estudo/ } \\
\text { Grupos }\end{array}$ \\
\hline $\begin{array}{l}\text { Könönen et al. } \\
(1999)^{20}\end{array}$ & Longitudinal & $\begin{array}{l}\text { Análise das amostras } \\
\text { de saliva não estimu- } \\
\text { lada de bebês edên- } \\
\text { tulos (no período } \\
\text { inicial) aos } 2,6 \text { e } 12 \\
\text { meses de idade } \\
\text { quanto a colonização } \\
\text { de micro-organismos } \\
\text { anaeróbios. }\end{array}$ \\
\hline
\end{tabular}

Cephas et al. $(2011)^{16}$

Experimental (Laboratorial)

Nelson-Filho et al. $(2013)^{14}$

\section{Experimental (Laboratorial)}

Análise das amostras de saliva para pirosequenciamento do microbioma de 5 bebês edêntulos (média de 4,6 meses) e de suas mães ou cuidadoras primárias (média de idade de 30,8 anos)

Amostras coletadas da microbiota oral de bebês a termo e saudáveis nos seguintes períodos: De 10 min e 8h após o nascimento; $8 \mathrm{~h}$ e $16 \mathrm{~h}$ após o nascimento; 16h e 24 h após o nascimento e $24 \mathrm{~h}$ e $53 \mathrm{~h}$ após o nascimento.
Amostra

44 bebês

saudáveis

(com 2, 6

e 12 meses

de idade)

5 bebês edêntulos

(média de

4,6 meses)

e suas

mães ou

cuidadoras

primárias

(média de

idade de

30,8 anos)

51 bebês

(81 amostras cole-

tadas da microbiota

oral)

a

\section{Principais resultados encontrados}

Bactéria anaeróbias foram encontradas em $80 \%$ dos bebês com 2 meses (Veillonella spp. foi a mais frequente), em 93\% dos bebês com 6 meses e em 100\% dos bebês com 12 meses. Foi concluído que uma vez colonizados, as bactérias persistem na cavidade bucal e a frequência de espécies anaeróbias aumenta durante o primeiro ano de vida.

O gênero Streptococcus
foi mais prevalente na
saliva dos bebês $(62,2 \%)$
comparado à saliva das
mães (20,4\%); Veillonella,
e Neisseria também foram
gêneros prevalentes na
saliva dos bebês. Embora
o microbioma salivar dos
adultos tenham maior
contagem de micro-orga-
nismos que os bebês, uma
rica comunidade bacte-
riana existe na cavidade
bucal destas crianças antes
da erupção dentária.

Entre 10 min e 8h: S. epidermidis foram identificados em 30,7\% amostras. Entre 8h e 16h: S. epidermidis (69,5\% das amostras) e Streptococci (56,5\%). Entre $16 \mathrm{~h}$ e $24 \mathrm{~h}$ foram detectados Streptococci $(85,9 \%)$, S. epidermidis (77,8\%) e $S$. aureus (37,0\%). Entre $24 \mathrm{~h}$ e 53h: Streptococci $(94,4 \%)$, S. epidermidis $(88,9 \%)$ e S. aureus (33,3\%). S. mutans não foi detectado. Foi sugerido a adoção de medidas de higiene para mães e profissionais de hospitais para evitar, no mínimo, o atraso da ocorrência de infecção por estes micro-organismos em recém-nascidos. 
Como pela busca nas bases de dados investigadas não foram encontrados estudos clínicos e/ou observacionais que investigaram o efeito da higienização no número de micro-organismos da cavidade bucal de bebês edêntulos, foi realizada uma busca nos livros texto de Odontopediatria redigidos em português, com o objetivo de analisar o que era preconizado pelos autores quanto à higienização da cavidade bucal dos bebês edêntulos. A Tabela 3 demonstra os protocolos de higienização da cavidade bucal dos bebês recomendados em cada livro texto, além das informações de como cada uma é indicada e quais são as referências citadas para tal recomendação.

Tabela 3: Relação dos conteúdos dos principais livros textos de Odontopediatria sobre a indicação da higiene bucal de bebês edêntulos, dispondo de como realizá-la e qual a referência indicada para o procedimento.

\begin{tabular}{|c|c|c|c|c|}
\hline Livro/ano & Autores & $\begin{array}{l}\text { Indica a higiene } \\
\text { bucal? }\end{array}$ & $\begin{array}{l}\text { Como é } \\
\text { preconizada } \\
\text { a higiene? }\end{array}$ & Referências \\
\hline $\begin{array}{l}\text { Odontopediatria: } \\
\text { bases para a prática } \\
\text { clínica }(2005)^{22}\end{array}$ & $\begin{array}{l}\text { Lea Assed } \\
\text { Bezerra da Silva }\end{array}$ & $\begin{array}{l}\text { Preconiza o início } \\
\text { da higienização } \\
\text { antes da erup- } \\
\text { ção do primeiro } \\
\text { dente. }\end{array}$ & $\begin{array}{l}\text { Gaze, escova, } \\
\text { dedeiras e fral- } \\
\text { das. Usar gaze } \\
\text { até a erupção } \\
\text { dos primeiros } \\
\text { molares, quando } \\
\text { então deve-se } \\
\text { introduzir o uso } \\
\text { da escova. }\end{array}$ & $\begin{array}{l}\text { Não } \\
\text { informado }\end{array}$ \\
\hline $\begin{array}{l}\text { Fundamentos de } \\
\text { Odontologia: } \\
\text { Odontopediatria } \\
(2009)^{23}\end{array}$ & $\begin{array}{l}\text { Antonio Carlos } \\
\text { Guedes Pinto, } \\
\text { Marcelo Bone- } \\
\text { cker e Célia } \\
\text { Regina Martins } \\
\text { Delgado Rodri- } \\
\text { gues }\end{array}$ & $\begin{array}{l}\text { Realizar a } \\
\text { limpeza para } \\
\text { desenvolver na } \\
\text { criança o hábito } \\
\text { de higienização } \\
\text { e remover restos } \\
\text { de leite. }\end{array}$ & $\begin{array}{l}\text { Gaze umedecida } \\
\text { em água fervida } \\
\text { ou soro fisioló- } \\
\text { gico, envolta do } \\
\text { dedo indicador } \\
\text { do responsável; } \\
\text { ou o uso de } \\
\text { dedeiras }\end{array}$ & $\begin{array}{l}\text { Não } \\
\text { informado }\end{array}$ \\
\hline $\begin{array}{l}\text { Odontopediatria na } \\
\text { primeira infância } \\
(2010)^{24}\end{array}$ & $\begin{array}{l}\text { Maria Salete } \\
\text { Nahás Pires } \\
\text { Corrêa }\end{array}$ & $\begin{array}{l}\text { Não recomenda } \\
\text { a higienização, } \\
\text { devido a ausên- } \\
\text { cia de evidências } \\
\text { científicas }\end{array}$ & Não informado & $\begin{array}{l}\text { Bonecker } \\
\text { e Corrêa } \\
(2013)^{25}\end{array}$ \\
\hline $\begin{array}{l}\text { Manual de referência } \\
\text { para procedimentos } \\
\text { clínicos em Odonto- } \\
\text { pediatria }(2013)^{26}\end{array}$ & $\begin{array}{l}\text { Maria de Lour- } \\
\text { des de Andrade } \\
\text { Massara e Paulo } \\
\text { Cesar Barbosa } \\
\text { Rédua }\end{array}$ & $\begin{array}{l}\text { Preconizado } \\
\text { que só se inicie } \\
\text { a higienização } \\
\text { após o primeiro } \\
\text { dente irromper. }\end{array}$ & Não informado & $\begin{array}{l}\text { Não } \\
\text { informado }\end{array}$ \\
\hline $\begin{array}{l}\text { Odontopediatria: } \\
\text { uma visão } \\
\text { contemporânea } \\
(2013)^{27}\end{array}$ & $\begin{array}{l}\text { Cristiane Duque } \\
\text { e colaboradores }\end{array}$ & $\begin{array}{l}\text { Iniciar antes } \\
\text { da presença } \\
\text { de dentes para } \\
\text { limpeza dos } \\
\text { resíduos do leite } \\
\text { e massagem das } \\
\text { gengivas. }\end{array}$ & $\begin{array}{l}\text { Gaze estéril ou } \\
\text { ponta e fralda do } \\
\text { bebê, embebi- } \\
\text { dos em água } \\
\text { filtrada ou o uso } \\
\text { de dedeiras. }\end{array}$ & $\begin{array}{l}\text { Não } \\
\text { informado }\end{array}$ \\
\hline
\end{tabular}




\begin{tabular}{|c|c|c|c|c|}
\hline Livro/ano & Autores & $\begin{array}{l}\text { Indica a higiene } \\
\text { bucal? }\end{array}$ & $\begin{array}{l}\text { Comoé } \\
\text { preconizada } \\
\text { a higiene? }\end{array}$ & Referências \\
\hline $\begin{array}{l}\text { Odontopediatria. } \\
\text { Série Abeno }(2014)^{28}\end{array}$ & $\begin{array}{l}\text { Isabela Almeida } \\
\text { Pordeus e Saul } \\
\text { Martins Paiva }\end{array}$ & $\begin{array}{l}\text { Preconiza que a } \\
\text { higienização seja } \\
\text { iniciada após o } \\
\text { irrompimento do } \\
\text { primeiro dente }\end{array}$ & Não informado & $\begin{array}{l}\text { Não } \\
\text { informado }\end{array}$ \\
\hline $\begin{array}{l}\text { Odontopediatria } \\
(2015)^{6}\end{array}$ & $\begin{array}{l}\text { Antônio Carlos } \\
\text { Guedes Pinto e } \\
\text { Anna Carolina } \\
\text { Volpi Mello- } \\
\text {-Moura }\end{array}$ & $\begin{array}{l}\text { Realizar higie- } \\
\text { nização, caso o } \\
\text { bebê não faça a } \\
\text { ingestão exclu- } \\
\text { siva de leite } \\
\text { materno, para } \\
\text { promover micro- } \\
\text { biota saudável na } \\
\text { cavidade }\end{array}$ & $\begin{array}{l}\text { Compressa de } \\
\text { gaze ou ponta } \\
\text { de fralda úmida, } \\
\text { com massagem } \\
\text { delicada e posi- } \\
\text { ção confortável } \\
\text { para o bebê. } \\
\text { Realizar uma vez } \\
\text { ao dia. }\end{array}$ & $\begin{array}{l}\text { Não } \\
\text { informado }\end{array}$ \\
\hline $\begin{array}{l}\text { Odontopediaria: } \\
\text { A transdisciplina- } \\
\text { ridade na saúde } \\
\text { integral da criança } \\
(2016)^{29}\end{array}$ & $\begin{array}{l}\text { Liliana Takaoka, } \\
\text { Lúcia Coutinho } \\
\text { e Rosa Maria Eid } \\
\text { Weiler }\end{array}$ & $\begin{array}{l}\text { Preconiza que } \\
\text { seja realizada } \\
\text { após o irrom- } \\
\text { pimento do } \\
\text { primeiro dente, } \\
\text { pois este proce- } \\
\text { dimento poderia } \\
\text { remover anticor- } \\
\text { pos da cavidade } \\
\text { bucal do bebê. }\end{array}$ & Não informado & $\begin{array}{l}\text { Não } \\
\text { informado }\end{array}$ \\
\hline
\end{tabular}

\section{DIsCUSSÃo}

De acordo com a busca realizada na presente revisão não foram encontrados estudos clínicos (randomizados ou não) e observacionais, a respeito do efeito da higienização da cavidade bucal de bebês edêntulos na microbiota. Este fato impossibilitou o desenvolvimento de uma revisão sistemática da literatura sobre o referido assunto e demonstrou a necessidade de investigação científica sobre a indicação da higiene bucal em bebês edêntulos. Contudo, 5 estudos sobre a colonização precoce de bactérias na cavidade bucal de bebês e 1 sobre o papel das imunoglobulinas salivares presentes no meio bucal foram encontrados ${ }^{14,16,18-21}$, fornecendo bases científicas para auxiliar na discussão sobre a indicação ou não da higienização da cavidade bucal de bebês edêntulos. Uma descrição resumida destes artigos foi demonstrada na Tabela 2.

A partir dos resultados destes artigos que investigaram a colonização microbiana na cavidade bucal de bebês edêntulos ${ }^{14,16,18-20}$, observa-se que o número e a diversidade dos micro-organismos aumentam com o tempo. No trabalho de Nelson-Filho et al. ${ }^{14}$, no período de $10 \mathrm{~min}$ a 8 h foi detectado apenas $S$. epidermidis em $30,8 \%$ das amostras, enquanto que no período de $24 \mathrm{~h}$ a $53 \mathrm{~h}$, a porcentagem deste micro-organismo aumentou para $88,9 \%$. No estudo de Long e Swenson ${ }^{18}$, a aderência $S$. salivaris e $S$. mitis nas células epiteliais coletadas da língua e mucosa da bochecha de bebês com menos de 12 horas de idade foi observada após a incubação por $30 \mathrm{~min}$. Além disso, pela coleta de saliva de 44 bebês, Könönen et al. ${ }^{20}$ detectaram bactérias anaeróbicas em $80 \%$ dos bebês com 2 meses, e aos 6 meses essa porcentagem passou para $93 \%$ e aos 12 meses todos os bebês apresentavam bactérias anaeróbicas. Já no 
estudo de Cephas et al. ${ }^{16}$, Streptococcus, Veillonella e Neisseria foram os três gêneros mais prevalentes na cavidade bucal dos bebês com média de idade de 4,6 meses.

A presença de subclasses de imunoglobulinas IgA (IgA, IgA1, IgA2) na saliva de bebês edêntulos e crianças foi investigado por Tappuni e Challacombe ${ }^{21}$, de forma que o grupo de bebês edêntulos apresentou as concentrações mais baixas de todas as subclasses de IgA com relação aos outros dois grupos (mães e crianças). Esse resultado é importante, pois a imunoglobulina IgA é a primeira linha de defesa imune da mucosa bucal contra patógenos ${ }^{12}$. Sendo assim, a higienização precoce da cavidade bucal dos bebês edêntulos poderia interferir nos níveis de imunoglobulinas presentes, alterando a proteção da mucosa, principalmente dos bebês que ainda não apresentam grandes quantidades de IgA salivar ou aqueles que não são alimentados por aleitamento materno ${ }^{13}$.

Dois estudos investigaram em conjunto a saliva das mães e dos bebês ${ }^{16,19}$. Apenas o estudo de Könönen et al. ${ }^{19}$ observou correlação positiva entre a concentração bacteriana das mães com a dos bebês. Foi ressaltado que as mães e os enfermeiros deveriam proceder com medidas de higiene gerais para evitar a transmissão de micro-organismos para os bebês, como a lavagem das mãos e seios antes de oferecer o leite materno, já que os bebês apresentam um sistema imune imaturo e alto risco para o desenvolvimento de infecções. Essa recomendação é relevante comparada a higiene diretamente da cavidade bucal do bebê edêntulo, na qual a limpeza poderia interferir nos níveis de IgA como mencionado anteriormente ${ }^{12}$.

O estudo de Cephas et al. ${ }^{16}$ também questionou os responsáveis sobre às práticas de higiene bucal dos bebês edêntulos. Todos informaram que realizavam a higiene nos bebês utilizando escovas de dedo ou panos, e alguns associavam com uso de água. Devido à presença de colonizadores tardios, como o Fusobacterium nucleatum, além de micro-organismos que são associados a cárie da primeira infância, como a Veillonella parvula na saliva dos bebês ${ }^{30}$ os autores entenderam que patógenos podem se instalar na cavidade bucal dos bebês edêntulos e concluíram que a higiene bucal antes da erupção do primeiro dente seria necessária. Entretanto vale ressaltar que a prevalência de $S$. mutans foi muito baixa nos bebês do estudo (0,0001\% de todas as espécies encontradas) e este é o colonizador primário da doença cárie ${ }^{12}$. Além disso, embora este estudo tenha realizado pirosequenciamento para filogeneticamente caracterizar o microbioma bacteriano salivar de bebês edêntulos (sendo provavelmente uma metodologia de custo elevado), o número de participantes foi baixo $(n=5)$.

A prevenção da cárie da primeira infância é umas das principais justificativas utilizadas para que alguns profissionais indiquem a higiene bucal em bebês edêntulos ${ }^{8-11}$. A bactéria primária para desenvolvimento desta doença é $S$. mutans ${ }^{12}$, porém Nelson-filho et al. ${ }^{14}$ relataram que não foi detectado $S$. mutans nas amostras de microbiota de bebês edêntulos. Long e Swenson ${ }^{18}$ mostraram que $S$. mutans mostrou baixa ou nenhuma aderência às células epiteliais coletadas da língua e mucosa da bochecha dos bebês. Outros micro-organismos foram encontrados na cavidade bucal de bebês edêntulos e que são associados com a cárie da primeira infância, como encontrado no estudo de Könönen et al. ${ }^{20}$ que identificaram Veillonella ssp. (o micro-organismo mais prevalente nas amostras) e Lactobacillus ssp., na saliva dos bebês edêntulos de 2 meses de idade. No estudo de Cephas et al. ${ }^{16}$, Veillonella ssp. também foi muito prevalente na saliva dos 5 bebês edêntulos investigados. Embora presentes na cavidade bucal, apenas os micro-organismos não são capazes de iniciar o processo carioso, visto que esta é uma patologia multifatorial ${ }^{2}$.

Baseado nesta colonização precoce de micro-organismos na cavidade bucal dos bebês, profissionais de saúde e livros textos de Odontopediatria (Tabela 3) preconizam a higienização da cavidade, mesmo antes da erupção dentária ${ }^{23,26}$, visando promover a limpeza das mucosas bucais e língua e habituar os bebês com a escovação e limpeza após a erupção dos dentes. A limpeza seria realizada para prevenir colonizações bacterianas, que pudessem servir como reservatórios para colonização de micro-organismos patogênicos ${ }^{16}$. 
Dos oito livros textos investigados (Tabela 3), somente 4 indicaram a higienização com gaze embebida em água filtrada, porém também não foram citadas as referências que justificassem esta recomendação ${ }^{6,22,23,27}$, incluindo até uma indicação de realizar a higiene em bebês edêntulos até a erupção dos primeiros dentes ${ }^{22}$. Este resultado é relevante e merece ser destacado, pois na grande maioria das vezes, os profissionais de saúde buscam sanar suas dúvidas em livros textos, de modo a realizar os procedimentos clínicos com base no que é preconizado nos livros. Os outros livros textos ${ }^{24,26,28,29}$ (Tabela 3) não preconizaram a higiene na cavidade bucal de bebês edêntulos, justamente pelo fato de não existirem evidências científicas que suportassem a indicação da mesma, além de ressaltarem o efeito protetor do leite materno na mucosa bucal.

Nos primeiros meses de vida, os médicos e os enfermeiros são os profissionais de saúde que possuem maior contato com bebês, pois dificilmente os pais e responsáveis levam os bebês ao consultório odontológico antes da erupção dentária. Assim, é essencial que esses profissionais saibam orientar os pais quanto à saúde bucal dos bebês. Porém, Oliveira et al. ${ }^{11}$ e Valente e Silva et $a l .{ }^{10}$ relataram que a maioria dos médicos responderam em questionários que havia necessidade de iniciar a higiene bucal antes da erupção dos dentes. De acordo com o estudo de Andrade et al. ${ }^{8}, 29$ profissionais (entre médicos e enfermeiros) responderam que não sabiam como deveria ser feita a higienização da cavidade bucal de crianças de 0 a 36 meses. Já, Schalka e Rodrigues ${ }^{9}$ mostraram que a maioria dos médicos entrevistados concordaram que apenas seria necessária a higiene após a erupção do primeiro dente. Os resultados desses estudos mostram a grande variação existente, entre os médicos e os enfermeiros, quanto a indicação ou não da higiene bucal antes da erupção dos dentes. Além disso, ainda existe um desconhecimento quanto ao momento mais propício para indicá-la, não havendo entre esses profissionais a padronização da informação, demonstrando mais uma vez a forte necessidade de estudos clínicos para fornecer bases científicas sobre o tema em questão.

Assim sendo, o protocolo de higienização da cavidade bucal edêntula, recomendado por artigos e por livros textos de odontopediatria merece uma atenção e reflexão especial antes de sua indicação, já que não existem evidências científicas que comprovem sua eficácia clínica. Outro fator que deve ser avaliado é que na cavidade edêntula não existe superfícies dentárias não descamativas para a colonização das bactérias cariogênicas e com a limpeza da cavidade bucal pode, também, haver comprometimento da proteção pela interferência nos níveis de IgA. Poderia ser interessante realizar a higiene oral em bebês edêntulos com gaze ou fralda umedecida em água filtrada, uma vez ao dia, aos 6 meses de idade (próximo a erupção dos primeiros dentes), apenas para acostumar a criança com a manipulação da cavidade bucal e higiene. Porém, também não existem evidências que suportem essa recomendação.

\section{ConclusÃo}

Diante dos dados da presente revisão crítica, não existem estudos primários que avaliaram o efeito da higienização na microbiota bucal em bebês edêntulos. Desta forma, torna-se, de extrema necessidade a condução de estudos clínicos com o propósito de se obter evidências científicas sólidas sobre a indicação ou não da higienização da cavidade bucal de bebês edêntulos, proporcionando a prática clínica baseada em evidências e guiando a implementação de medidas de promoção de saúde bucal na primeira infância.

\section{CONFLITO DE INTERESSES}

Os autores declaram não haver conflito de interesses. 


\section{REFERÊNCIAS}

1. Brasil. Ministério da Saúde. SB Brasil 2010: Pesquisa Nacional de Saúde Bucal: resultados principais. Brasília; 2012.

2. Law $V$, Seow WK, Townsend G. Factors influencing oral colonization of mutans streptococci in young children. Aust Dent ]. 2007 Jun;52(2):93-100.

3. American Academy on Pediatric Dentistry. Policy on early childhood caries (ECC): classifications, consequences, and preventive strategies. Pediatr Dent. 2017 Sep;39(6):59-61.

4. Wright JT, Hanson N, Ristic H, Whall CW, Estrich CG, Zentz RR. Fluoride toothpaste efficacy and safety in children younger than 6 years: a systematic review. J Am Dent Assoc. 2014 Feb;145(2):182-9.

5. Martinez-Mier EA, Tenuta LMA, Carey CM, Cury JA, Van Loveren C, Ekstrand KR, et al. European Organization for Caries Research Workshop: methodology for determination of potentially available fluoride in toothpastes. ORCA Fluoride in Toothpaste Analysis Work Group. Caries Res. 2018;53(2):119-36.

6. Guedes-Pinto AC, Mello-Moura, AC. Odontopediatria. 9. ed. São Paulo: Editora Santos; 2015.

7. Caufield PW, Dasanayake AP, Li Y, Pan Y, Hsu ], Hardin JM. Natural history of Streptococcus sanguinis in the oral cavity of infants: evidence for a discrete window of infectivity. Infect Immun. 2000 Jul;68(7):4018-23.

8. Andrade PHA, Junior JKO, Penha ES, Almeida MSC, Costa CHM. Conhecimento de médicos e enfermeiros sobre saúde bucal na primeira infância. Rev Bras Ciênc Saúde. 2016;20(2):133-40.

9. Schalka MMS, Rodrigues CRMD. A importância do médico pediatra na promoção de saúde bucal. Rev Saúde Públ. 1996;30(2):179-86.

10. Valente e Silva CSD, Benedetto MS, Bonini GAVC, Imparato JCP, Politano GT. Conhecimento de pediatras sobre a saúde bucal em Belo Horizonte. O que realmente precisa saber? Rev Assoc Paul Cir Dent. 2014;68(2):126-31.

11. Oliveira IMB, Almeida MEL, Menezes LMB, Teixeira AKM. Saúde bucal na primeira infância: conhecimentos e práticas de médicos residentes em saúde da família. Sanare Rev Pol Publ. 2010;9(2):73-80.

12. Merglova V, Koberova-Ivancakova R, Broukal Z, Dort]. The presence of cariogenic and periodontal pathogens in the oral cavity of one-year-old infants delivered pre-term with very low birthweights: a case control study. BMC Oral Health. 2014 Sep 1;14:109.

13. Hurley E, Mullinsa D, Barretta MP, O'Sheac CA, Kinironsb M, Ryand CA, et al. The microbiota of the mother at birth and its influence on the emerging infant oral microbiota from birth to 1 year of age: a cohort study. J. Oral Microbiol. 2019;11(1):1599652.

14. Nelson-Filho P, Borba IG, Mesquita KSF, Silva RAB, Queiroz AM, Silva LAB. Dynamics of microbial colonization of the oral cavity in newborns. Braz Dent ]. 2013 Jul-Aug;24(4):415-9.

15. Rotimi VO, Duerden BI. The development of the bacterial flora in normal neonates. ] Med Microbiol. 1981 Feb;14(1):51-62.

16. Cephas KD, Kim J, Mathai RA, Barry KA, Dowd SE, Meline BS, et al. Comparative analysis of salivary bacterial microbiome diversity in edentulous infants and their mothers or primary care givers using pyrosequencing. Plos One. 2011 Aug;6(8):e23503.

17. Martínez SP, Islas ]LH, Torres MPE, Alonzo IEP, Candiani AC, Correa D, et al. Immunoglobulin concentrations in plasma and saliva during the neonatal period. Pediatr Neonatol. 2016 ]un;57:213-8.

18. Long SS, Swenson RM. Determinants of the developing oral flora in normal newborns. Appl Environ Microbiol. 1976 Oct;32(4):494-7.

19. Könönen E, Jousimies-Somer H, Asikainen S. Relationship between oral gram-negative anaerobic bacteria in saliva of the mother and the colonization of her edentulous infant. Oral Microbiol Immunol. 1992 Oct;7(5):273-6.

20. Kononen E, Kanervo A, Takala A, Asikainen S, Jousimies-Somer H. Establishment of oral anaerobes during the first year of life. J Dent Res. 1999 oct; 78(10):1634-9.

21. Tapuni AR, Challacombe S]. A comparison of salivary immunoglobulin A (IgA) and IgA subclass concentrations in predentate and dentate children and adults. Oral Microbiol Imunol.1994 Jun;9(3):142-5.

22. Assed LBS. Odontopediatria: bases científicas para a prática clínica. São Paulo: Artes Médicas; 2005.

23. Guedes-Pinto AC, Bonecker M, Rodrigues CRMD. Fundamentos de odontología: odontopediatria. São Paulo: Santos; 2009

24. Corrêa MSNP. Odontopediatria na primeira infância. 2. ed. São Paulo: Santos; 2010

25. Bonecker MJS, Corrêa MSN. Medidas educativas preventivas para o tratamento integral do bebê. Odontologia, conhecimento e arte. São Paulo: Artes Médicas; 2013.

26. Massara MLA, Redua PCB. Manual de referência para procedimentos clínicos em odontopediatria. São Paulo: Santos; 2013.

27. Duque C, Teixeira CAS, Ribeiro AA, Ammari MM, Abreu FV, Antunes LAA. Odontopediatria: uma visão contemporânea. São Paulo: Santos; 2013 
28. Pordeus IA, Paiva SM. Odontopediatria. Rio de Janeiro: Artes Médicas; 2014. 118 p. (ABENO: Odontologia Essencial: Parte Clínica).

29. Takakoa L, Coutinho L, Weiler RME. Odontopediatria: a transdisciplinaridade na saúde integral da criança. Barueri: Manole; 2016.

30. Carvalho FG, Silva DS, Hebling ], Spolidorio LC, Spolidorio DMP. Presence of mutans streptococci and Candida spp. in dental plaque/dentine of carious teeth and early childhood caries. Arch Oral Biol. 2006 Jun;51(11):1024-8. 